\title{
Genome scan detects quantitative trait loci affecting female fertility traits in Danish and Swedish Holstein cattle
}

\author{
J. K. Höglund, ${ }^{*} † \ddagger$ B. Guldbrandtsen, ${ }^{*}$ G. Su, ${ }^{*}$ B. Thomsen, ${ }^{*}$ and M. S. Lund ${ }^{* 1}$ \\ *Aarhus University, Faculty of Agricultural Sciences, Department of Genetics and Biotechnology, PO Box 50, 8830 Tjele, Denmark \\ †VikingGenetics, PO Box 64, S-532 21 Skara, Sweden \\ ¥Sveriges Lantbruksuniversitet, PO Box 7070, 75007 Uppsala, Sweden
}

\section{ABSTRACT}

Data from the joint Nordic breeding value prediction for Danish and Swedish Holstein grandsire families were used to locate quantitative trait loci (QTL) for female fertility traits in Danish and Swedish Holstein cattle. Up to 36 Holstein grandsires with over 2,000 sons were genotyped for 416 microsatellite markers. Single trait breeding values were used for 12 traits relating to female fertility and female reproductive disorders. Data were analyzed by least squares regression analysis within and across families. Twenty-six QTL were detected on 17 different chromosomes. The best evidence was found for QTL segregating on Bos taurus chromosome (BTA)1, BTA7, BTA10, and BTA26. On each of these chromosomes, several QTL were detected affecting more than one of the fertility traits investigated in this study. Evidence for segregation of additional QTL on BTA2, BTA9, and BTA24 was found.

Key words: quantitative trait locus, genome-wide scan, female fertility

\section{INTRODUCTION}

Female fertility has been declining in recent decades in the Holstein cattle populations (Sørensen et al., 2007). Improving female fertility is becoming more and more important as the consequences of impaired fertility include additional inseminations, higher veterinary costs, increased culling rate, and higher replacement costs.

Traditional selection methods to improve fertility have not been able to prevent this decline in female fertility (Strudsholm et al., 2007). There are several reasons for this. First, heritabilities for fertility traits are generally low (ranging from 2 to $4 \%$ for Holstein populations in the Nordic countries; Strudsholm et al., 2007), they have sex-limited expression, and some of

Received February 18, 2008.

Accepted December 12, 2008

${ }^{1}$ Corresponding author: Mogens.Lund@agrsci.dk them are expressed late in life. This in itself causes genetic gain to be slow at best. Furthermore, the genetic correlations between fertility and production traits are generally unfavorable. Genetic correlations between milk yield traits and fertility traits are in the range of -0.2 to -0.5 (Pryce et al., 1997; Dematawewa and Berger, 1998; Roxström et al., 2001). Given the high economic weight put on production traits in most countries' breeding programs, this has lead to the continuing decline in female fertility. Even the much higher weight on female fertility in breeding goals in Nordic countries has not been sufficient to offset this trend.

Identification of QTL for fertility traits would contribute to improve the efficiency of selection for fertility traits. Expression of fertility traits is sex-limited. The AI bulls have to be progeny-tested before they are proven for fertility traits. Hence, it could be a significant advantage to obtain information of young bulls' breeding values for fertility traits at an early age. Genetic gain could then be increased. Detection of QTL for fertility traits could make information available at an early age through the use of marker-based tests. Even if the use of genomic selection should become widespread, QTL with effects on low heritability traits such as fertility will remain valuable particularly where recordings for fertility traits are not available.

Several studies have reported the detection of QTL for fertility traits (Schrooten et al., 2000; Kühn et al., 2003; Ashwell et al., 2004; Schnabel et al., 2005; Holmberg and Andersson-Eklund, 2006). Generally, overlap between the QTL detected in different studies is incomplete. In part, this may be caused by insufficient statistical power of detection studies due to the low heritability of the traits. Hence, the probability of obtaining strong evidence for the same QTL in multiple studies will be greatly reduced. Also, trait definitions and computational procedures for estimating breeding values differ among countries, which in turn may lead to detection of different QTL between countries.

International cooperation can overcome some of these problems. Cattle breeding organizations in Denmark, Sweden, and Finland have established a joint breed- 
ing value estimation system, the Nordic Cattle Genetic Evaluation. Trait definitions have been standardized across the countries. The Nordic countries record a wide range of fertility traits. In this study, we include 12 different measures of female fertility. Simultaneously, combining data across a larger base of recorded data will lead to more precise prediction of breeding values. This will in turn improve the statistical power to detect QTL. For genetic polymorphisms with effects on several traits, detection of QTL for several biologically related traits can lend each other added support. The large number of fertility-related traits available in the Nordic Cattle Genetic Evaluation can therefore be exploited to gain additional confidence in detections of QTL.

The objective of this study was to detect QTL for multiple female fertility traits in Danish and Swedish populations of Holstein cattle.

\section{MATERIALS AND METHODS}

\section{Population}

A total of 36 Danish and Swedish Holstein grandsires with more than 16 offspring-tested sons were analyzed in a granddaughter design (Weller et al., 1990). Of these 36 families, 29 were tested only in Denmark, 2 only in Sweden, and 5 across the countries. The sires with offspring in both countries had twice as many sons tested in Denmark as in Sweden. The number of sons per grandsire ranged from 16 to 160 with an average of 61 sons per grandsire family. Of the grandsire families, 5 had less than 30 sons, 14 had between 31 and 60 sons, 9 had between 61 and 100 sons, whereas 5 had more than 100 sons. In total 2,182 sons were genotyped.

\section{Marker Data}

The genome was screened using 416 microsatellite markers representing a total of $3,179 \mathrm{cM}$ with an average marker spacing of $7.64 \mathrm{cM}$. All 29 autosomes were typed for an average of 14 markers (Table 1). The number of grandsire families typed varies between chromosomes because chromosomes considered interesting in past QTL mapping projects varied (Table 1). As a measure of the amount of available marker information, the average number of heterozygote markers in the grandsires included in this study is listed in Table 1. Markers and their positions were taken from the USDA Cattle Genome Mapping Project (http://www.marc. usda.gov/genome/cattle/cattle.html).

Genomic DNA was extracted from semen or blood samples (DNeasy tissue extraction kit, Qiagen, Valencia, CA) and used in multiplex PCR in which 4 to 10 microsatellite markers were amplified. Polymerase chain reactions $(15 \mu \mathrm{L})$ were performed in a 96-well thermal cycler (GeneAmp PCR System 9700, Applied Biosystems, Foster City, CA) using $2.5 \mathrm{mM} \mathrm{MgCl}_{2}$, $0.25 \mathrm{~m} M$ deoxynucleoside triphosphate, $0.3 \mu M$ of each forward primer, $0.3 \mu \mathrm{M}$ of each reverse primer, $0.75 \mathrm{U}$ of TEMPase DNA polymerase (VWR-Bie \& Berntsen, Denmark), and 30 to $100 \mathrm{ng}$ of genomic DNA in $1 \times$ TEMPase PCR buffer (VWR-Bie \& Berntsen). An initial denaturing step at $94^{\circ} \mathrm{C}$ for 15 min was followed by 10 touchdown cycles at $95^{\circ} \mathrm{C}$ for $30 \mathrm{~s}$, annealing at 67 to $58^{\circ} \mathrm{C}$ for $1.5 \mathrm{~min}$, and extension at $72^{\circ} \mathrm{C}$ for $45 \mathrm{~s}$; then 25 cycles at $95^{\circ} \mathrm{C}$ for $30 \mathrm{~s}$, annealing at $58^{\circ} \mathrm{C}$ for $1.5 \mathrm{~min}$, extension at $72^{\circ} \mathrm{C}$ for $45 \mathrm{~s}$, and ending with $72^{\circ} \mathrm{C}$ for $20 \mathrm{~min}$. The products of PCR were analyzed on an automated sequence analyzer (ABI 3730 DNA Analyzer, Applied Biosystems). Alleles were assigned using the GeneMapper software, version 3.7 (Applied Biosystems).

\section{Phenotypic Data}

Single-trait breeding values (STBV) were custom made by the Nordic Cattle Genetic Evaluation. The STBV was calculated for each animal using BLUP procedures and a sire model. The STBV were adjusted for the same systematic environmental effects as in the official routine evaluations. However, the correlation to other traits was set to 0 and calculated without pedigree information. This is to avoid information from phenotypes of correlated traits to affect results of a particular trait. The STBV were calculated for 12 fertility traits. For details of the phenotypes recorded and models used in breeding value prediction, see http://www. nordicebv.info/Routine+evaluation/Fertility+traits/ Fertility+traits.htm and Ancker et al. (2006). The predicted breeding values for sires were predicted on data for the first to third parity in cows. The STBV were available from national evaluation separately for cows $\left({ }^{\mathrm{C}}\right)$ and heifers $\left({ }^{\mathrm{H}}\right)$ for number of inseminations per conception (or culling) $\left(\mathbf{A I S}{ }^{\mathbf{C}}\right.$ and $\mathbf{A I S}^{\mathbf{H}}$ ), 56-d nonreturn rate $\left(\mathbf{N R R} \mathbf{R}^{\mathbf{C}}\right.$ and $\left.\mathbf{N} \mathbf{R} \mathbf{R}^{\mathbf{H}}\right)$, days from first to last insemination $\left(\mathbf{I F L}^{\mathbf{C}}\right.$ and $\mathbf{I F L} \mathbf{L}^{\mathbf{H}}$ ), and heat strength $\left(\mathbf{H S T}^{\mathrm{C}}\right.$ and $\left.\mathbf{H S T}^{\mathbf{H}}\right)$. Length in days of the interval from calving to first insemination (ICF) is only defined for cows. It should be noted that HST was assessed subjectively by the individual farmer on a scale from 1 to 5 , and it was only recorded in Sweden.

Because of differences between the Danish and Swedish recording systems for fertility treatments in the first 3 parities (FRT1, FRT2, and FRT3), only records from Denmark were used in this study. In Denmark, fertility treatments are recorded by veterinarians and trained AI technicians. Fertility treatments include hormonal reproductive disorders, ovarian cyst treatments, and in- 
HÖGLUND ET AL.

Table 1. Overview of marker information by chromosome

\begin{tabular}{|c|c|c|c|c|}
\hline 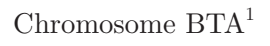 & Markers & $\operatorname{Length}^{2}(\mathrm{cM})$ & Heterozygote $^{3}$ markers & Families $^{4}$ \\
\hline 1 & 23 & 189 & 10.9 & $29 \mathrm{DK}, 7 \mathrm{SE}$ \\
\hline 2 & 10 & 139 & 6.4 & $14 \mathrm{DK}, 7 \mathrm{SE}$ \\
\hline 3 & 28 & 171 & 9.9 & $29 \mathrm{DK}, 7 \mathrm{SE}$ \\
\hline 4 & 8 & 104 & 5.1 & $14 \mathrm{DK}, 7 \mathrm{SE}$ \\
\hline 5 & 24 & 181 & 7.3 & $29 \mathrm{DK}, 7 \mathrm{SE}$ \\
\hline 6 & 8 & 113 & 4.1 & $14 \mathrm{DK}, 7 \mathrm{SE}$ \\
\hline 7 & 22 & 138 & 7.5 & $29 \mathrm{DK}, 7 \mathrm{SE}$ \\
\hline 8 & 10 & 197 & 3.6 & $29 \mathrm{DK}, 7 \mathrm{SE}$ \\
\hline 9 & 26 & 113 & 6.9 & $29 \mathrm{DK}, 7 \mathrm{SE}$ \\
\hline 10 & 17 & 142 & 8.0 & $29 \mathrm{DK}, 7 \mathrm{SE}$ \\
\hline 11 & 14 & 112 & 6.3 & $29 \mathrm{DK}, 7 \mathrm{SE}$ \\
\hline 12 & 6 & 103 & 4.9 & $14 \mathrm{DK}, 7 \mathrm{SE}$ \\
\hline 13 & 6 & 117 & 4.7 & $14 \mathrm{DK}, 7 \mathrm{SE}$ \\
\hline 14 & 10 & 108 & 3.5 & $19 \mathrm{DK}, 7 \mathrm{SE}$ \\
\hline 15 & 17 & 103 & 6.7 & $29 \mathrm{DK}, 7 \mathrm{SE}$ \\
\hline 16 & 17 & 114 & 5.2 & $29 \mathrm{DK}, 7 \mathrm{SE}$ \\
\hline 17 & 11 & 93 & 4.9 & $15 \mathrm{DK}, 7 \mathrm{SE}$ \\
\hline 18 & 22 & 124 & 7.9 & $29 \mathrm{DK}, 7 \mathrm{SE}$ \\
\hline 19 & 8 & 133 & 5.2 & $14 \mathrm{DK}, 7 \mathrm{SE}$ \\
\hline 20 & 10 & 94 & 3.8 & $14 \mathrm{DK}, 7 \mathrm{SE}$ \\
\hline 21 & 22 & 86 & 5.7 & $29 \mathrm{DK}, 7 \mathrm{SE}$ \\
\hline 22 & 6 & 85 & 3.9 & $14 \mathrm{DK}, 7 \mathrm{SE}$ \\
\hline 23 & 17 & 65 & 5.6 & $29 \mathrm{DK}, 7 \mathrm{SE}$ \\
\hline 24 & 14 & 55 & 4.2 & $14 \mathrm{DK}, 7 \mathrm{SE}$ \\
\hline 25 & 6 & 80 & 2.9 & $14 \mathrm{DK}, 7 \mathrm{SE}$ \\
\hline 26 & 10 & 59 & 4.6 & $29 \mathrm{DK}, 7 \mathrm{SE}$ \\
\hline 27 & 13 & 44 & 7.9 & $29 \mathrm{DK}, 7 \mathrm{SE}$ \\
\hline 28 & 12 & 57 & 4.3 & $29 \mathrm{DK}, 7 \mathrm{SE}$ \\
\hline 29 & 19 & 60 & 7.9 & $29 \mathrm{DK}, 7 \mathrm{SE}$ \\
\hline Total & 416 & 3,179 & 5.9 & \\
\hline
\end{tabular}

fective reproductive disorders and consist of recordings of endometritis, metritis, and vaginitis treatments as well as treatments for abortion, uterine prolapse, uterine torsion, and other reproductive disorders. The unit of measurement was number of recorded events. For fertility treatments, STBV were predicted separately for first, second, and third lactation. The STBV were estimated using total number of records within each lactation for each animal as the observed phenotype.

\section{QTL Analysis}

The traits were analyzed with the linear regression mapping procedure adapted from Haley and Knott (1992). All QTL analyses were done using the program GDQTL4 (unpublished) by one of the authors (Bernt Guldbrandtsen; source code available from the author, Bernt.Guldbrandtsen@agrsci.dk). The program GDQTL4 follows the following procedure. The linkage phases of the markers in the grandsires were determined based on the marker types of the sons. Marker allele frequencies were estimated using an expectation- maximization algorithm (Dempster et al., 1977). Segregation probabilities were calculated using all marker genotypes on the chromosome simultaneously, together with allele frequencies where segregation was ambiguous. The STBV were then regressed onto the segregation probabilities. The following regression model was applied in analyses both across and within families:

$$
Y_{i j}=\mu_{i}+b_{i}^{(p)}\left[2 X_{i j}^{(p)}-1\right]+e_{i j}^{(p)},
$$

where $Y_{i j}$ is the single trait estimated breeding value of son $j$ of grandsire $i, \mu_{i}$ is the overall mean of grandsire family $i, b_{i}^{(p)}$ is the regression coefficient within grandsire $i$ at position $p, X_{i j}^{(p)}$ is the probability that QTL allele 1 (using an arbitrary labeling of chromosomes) is transmitted from grandsire $i$ given all the informative markers of son $j$, and $e_{i j}^{(p)}$ is the residual effect given QTL position $p$. The regression coefficient $b_{i}^{(p)}$ is the expected deviation of the additive genetic value from 
the mean of the group of sons of an individual inheriting allele 1 . An individual inheriting allele 2 therefore has an expected deviation of $-b_{i}^{(p)}$. To obtain an estimate of the substitution effect, one should use $2 b_{i}^{(p)}$.

The tests conducted were of 2 types. First, a joint test was done. An $F$-statistic was calculated for each combination of trait and chromosome but across those grandsire families where both marker genotypes and STBV were available. Second, within-family tests were done: an $F$-statistic was calculated for those combinations of grandsire family, chromosome, and trait where both marker genotypes and STBV were available. The significance threshold was determined for each test individually by performing a permutation test with 1,000 permutations (Churchill and Doerge, 1994). A QTL was considered significant if it exceeded the 5\% chromosome-wise threshold in the permutation distribution. For each QTL significant in the joint test, the number of grandsire families individually significant at a 5\% level for a QTL on the same chromosome was counted.

Estimates of effect sizes were calculated by taking the average of the absolute values of the within-family estimates $\left[b_{i}^{(p)}\right]$ weighted by the number of sons across for only those families that met 2 criteria: 1 ) the family was significant in the within-family test and 2) where the maximum test statistic of the within-family test was attained within $25 \mathrm{cM}$ of the location of maximum test statistic in the joint test. Effects were standardized against the standard deviation of 10 used by the Nordic Cattle Genetic Evaluation for the STBV (see http:// www.nordicebv.info/ under "Presentation of EBVs").

For the set of joint tests, $q$-values were calculated following the method of Storey and Tibshirani (2003). The $q$-value is an estimate of the probability that a rejection of the null hypothesis in a given test would constitute a false positive. The $q$-values were calculated for the entire set of $P$-values across traits and chromosomes using the package "qvalue" (http://cran.r-project.org/ web/packages/qvalue/) for the R-package (http:// www.r-project.org).

\section{RESULTS AND DISCUSSION}

A total of 26 QTL significant at the $5 \%$ chromosomewise level were located on 17 different chromosomes in this genome scan (Table 2). Among the QTL reported here, 8 had effects on FRT, 2 on HST, 5 on NRR, 2 on AIS, and 9 on ICF. Effect estimates were in the range between 0.2 and 0.5 genetic standard deviations. False discovery rates, $q$-values for these QTL, varied between 0.133 and 0.471. On some chromosomes, several QTL were detected with different traits. If it is assumed that these reflect pleiotropic effects of the same underlying polymorphism, this provides support for these QTL.

On Bos taurus chromosome (BTA)1, evidence was found for the segregation of a QTL for fertility treatments in first lactation (FRT1, $P=0.002$ ) at $132 \mathrm{cM}$ and a QTL for ICF $(P=0.022)$ at $140 \mathrm{cM}$. Generally, reproductive health problems would lead to longer intervals before insemination can occur as well as potentially affect the success of the insemination. This with the proximity of the QTL peaks suggests that the QTL for the 2 traits may reflect the same underlying genetic variation. Schulman et al. (2008) have previously reported QTL for days open $(146 \mathrm{cM})$ and for fertility treatments $(151 \mathrm{cM})$ in Finnish Ayrshire cattle.

On BTA2, a QTL for $\mathrm{NRR}^{\mathrm{C}}$ was detected $(P=0.003$ or $q=0.160)$ at $3.9 \mathrm{cM}$ in the current study. This is close to a QTL reported by Schulman et al. (2008) in Finnish Ayrshire cattle for days open at $2 \mathrm{cM}$ on the same chromosome.

On BTA4, a QTL was detected $(P=0.028)$ at 43.2 cM with a $q$-value of 0.393 . However, no further support for this QTL was found in the literature.

On BTA7, QTL were detected for $\operatorname{AIS}^{\mathrm{H}}(P=0.035$ or $q=0.425)$ at $111 \mathrm{cM}$ and $\mathrm{HST}^{\mathrm{H}}(P=0.006$ or $q$ $=0.278)$ at $96 \mathrm{cM}$. Boichard et al. (2003) detected a QTL for success of insemination in daughters at 120 $\mathrm{cM}$ on this chromosome. Because AIS and insemination success will necessarily be related, the $\mathrm{AIS}^{\mathrm{H}}$ hit in the present study and the result of Boichard et al. (2003) may very well reflect the same genetic variation in the Danish-Swedish and French Holstein populations. The evidence for concordance with HST is not as strong because it is measured only in 7 Swedish families. Out of these 7 families, 2 were significant at a $5 \%$ level in family-wise tests on BTA7.

On BTA9, a highly significant QTL was found for IFL in cows $\left(P=0.001\right.$, IFL $\left.^{\mathrm{C}}\right)$ at $50 \mathrm{cM}$ and heifers $\left(\mathrm{IFL}^{\mathrm{H}}, P=0.018\right)$ at $5 \mathrm{cM}$ (i.e., far apart). Schrooten et al. (2000) and Holmberg and Andersson-Eklund (2006) reported a QTL for NRR near the marker TGLA73 (77.6 cM). Later, Holmberg et al. (2007) using combined linkage and linkage disequilibrium analysis fine-mapped this QTL to $27 \mathrm{cM}$. Holmberg and Andersson-Eklund (2006) also reported a QTL for heat intensity near the marker BMS817 $(42.5 \mathrm{cM})$. Nonreturn rate and IFL are intrinsically, related strongly suggesting that these authors may be observing the effect of the same QTL that is reported in the current study. The combination of low $q$-value for the IFL ${ }^{\mathrm{C}}$ QTL with an aggregation of QTL in other studies in the same region suggests that this QTL is real.

On BTA10, a QTL was detected for $\operatorname{IFL}^{\mathrm{C}}(P=0.026)$ at $90.8 \mathrm{cM}$. For this QTL, 7 grandsires segregated in 
Table 2. Overview of the QTL for the fertility traits significant in joint test

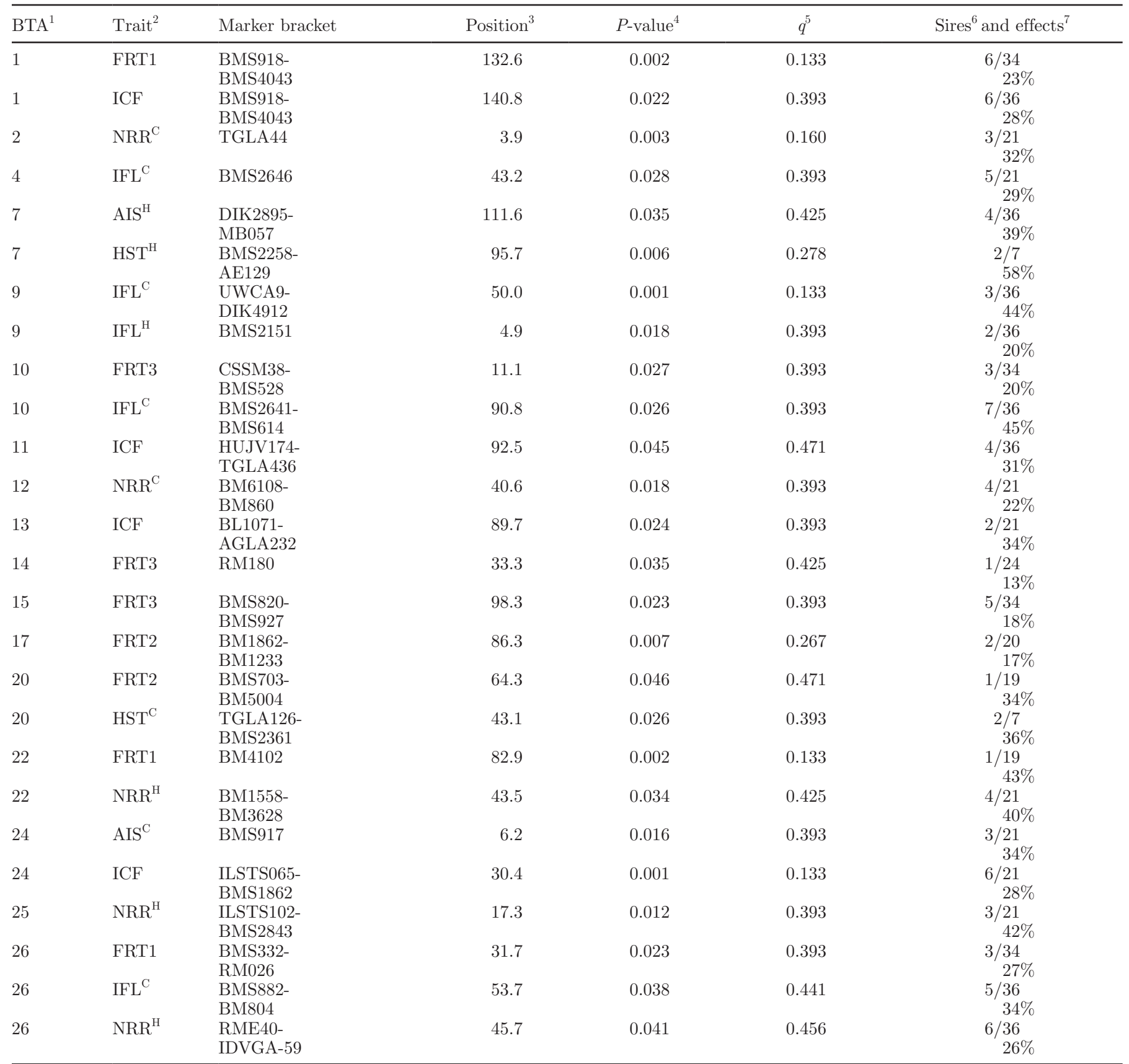

${ }^{1} \mathrm{BTA}=$ Bos taurus chromosome.

${ }^{2} \mathrm{FRT}=$ fertility treatments; ICF $=$ interval from calving to first insemination; NRR $=56$-d nonreturn rate; IFL $=$ interval from first to last insemination; AIS $=$ number of inseminations per conception; HST $=$ heat strength; ${ }^{\mathrm{C}}=\mathrm{cow} ;{ }^{\mathrm{H}}=$ heifer.

${ }^{3}$ Position of the maximum test statistic on the chromosome.

${ }^{4} P$-value for joint test.

${ }^{5} q$-value estimating probability of false positive.

${ }^{6}$ Number of families significant in within-family test/number of families analyzed.

${ }^{7}$ Average of within-family effect of QTL. 
within-family tests. Additionally, BTA10 only marginally fails to achieve significance for $\operatorname{AIS}^{\mathrm{C}}(P=0.077)$ in a joint test. However, out of the 7 sires segregating in within-family tests for the IFL ${ }^{\mathrm{C}}$ QTL, 5 were also found to segregate for $\mathrm{AIS}^{\mathrm{C}}$ in within-family tests. The most extreme test statistics for within-family tests for these traits were found within a range of $20 \mathrm{cM}$. A significant result was also found for FRT3 $(P=0.027)$ on BTA10. However, the maximum test statistic for FRT3 $(11 \mathrm{cM})$ was found far from the maximum for $\operatorname{IFL}^{\mathrm{C}}(90 \mathrm{cM})$. For each of these QTL, the $q$-value was high $(q=0.399)$. Boichard et al. (2003) reported a QTL for insemination success at $95 \mathrm{cM}$, which provides support to the present detection of a QTL for $\mathrm{IFL}^{\mathrm{C}}$ despite the very high $q$-value of the results reported here.

One QTL was detected on each of BTA11 $(q=0.471)$, BTA12 $(q=0.393)$, BTA13 $(q=0.393)$, and BTA15 ( $q$ $=0.393$ ). Each QTL was only found to be segregating in between 10 and $20 \%$ of the grandsire families examined. However, the QTL on BTA12 for $\mathrm{NRR}^{\mathrm{C}}$ at $49 \mathrm{cM}$ is supported by results from Schulman et al. (2008), who studied Finnish Ayrshire cattle detecting a QTL for days open at $47 \mathrm{cM}$.

On BTA14, a QTL was detected $(P=0.035)$ for third lactation reproductive diseases (FRT3) at $33 \mathrm{cM}$, but the $q$-value was high $(q=0.435)$. Ashwell et al. (2004) and Schnabel et al. (2005) detected a QTL for pregnancy rate on BTA14 at 11 and $60 \mathrm{cM}$, respectively. However, these traits are different and the peaks are far apart. These findings do not lend much support to our results.

On BTA17, a QTL was detected for FRT2 at $86.3 \mathrm{cM}$ $(P=0.007)$. Segregation was detected in only 2 out of 20 grandsire families examined. Again, the $q$-value was high $(q=0.267)$. No supporting evidence was found in the literature.

On BTA20, 2 QTL were detected for FRT2 $(P=$ $0.046)$ at $64.3 \mathrm{cM}$ and $\operatorname{HST}^{\mathrm{C}}(P=0.023)$ at $43 \mathrm{cM}$, respectively. For both these QTL, $q$-values were high (0.471 and 0.391). Only 1 out of 19 and 2 out of 7 grandsire families examined were segregating. However, Boichard et al. (2003) in the French population of Holstein cattle detected a QTL for insemination success at $75 \mathrm{cM}$.

On BTA 24, a highly significant $(P=0.001$ or $q=$ $0.133)$ QTL affecting ICF was detected at $6.2 \mathrm{cM}$. It was found to be segregating in 6 out of 24 grandsire families examined. On the same chromosome, a less significant $(P=0.016)$ QTL was located about $24 \mathrm{cM}$ apart for AIS $^{\mathrm{C}}$. This trait has not been extensively studied; therefore, no supporting evidence was found in the literature. Nonetheless, the relatively low $q$-value and high number of families found to be segregating means that the evidence for this QTL is fairly strong.
On BTA25, a QTL for $\mathrm{NRR}^{\mathrm{H}}$ was detected $(P=$ 0.012 ) at $17.3 \mathrm{cM}$ segregating in 3 out of 21 grandsire families examined with a $q$-value of 0.393 . Even though the number of families segregating is low and the $q$-value is high, Holmberg and Andersson-Eklund (2006) described a QTL for heat intensity at the same position.

On BTA26, significant results were found for $\mathrm{IFL}^{\mathrm{C}}$ $(P=0.012)$ at $53.7 \mathrm{cM}$, for $\mathrm{NRR}^{\mathrm{H}}(P=0.041)$ at 45.7 $\mathrm{cM}$, as well as for FRT1 $(P=0.038)$ at $31.7 \mathrm{cM}$. The QTL found for IFL ${ }^{\mathrm{C}}$ and for $\mathrm{NRR}^{\mathrm{H}}$ were found only 8 cM apart. For $\mathrm{IFL}^{\mathrm{C}}$, FRT1, and $\mathrm{NRR}^{\mathrm{H}}$, the peaks were found less than $25 \mathrm{cM}$ apart. The traits $\mathrm{IFL}^{\mathrm{C}}$ and $\mathrm{NRR}^{\mathrm{H}}$ both are measures of females' ability to conceive. It could therefore be the same QTL segregating for these fertility traits. Taken in isolation, the $q$-values for these QTL results were high (0.399 and 0.456). However, considering that the QTL locations for several QTL are close to each other, the results in combination become more convincing, assuming that they represent effects of the same underlying genetic polymorphism. None of the other studies reported QTL on this chromosome.

In summary, among the QTL candidates discussed combining results from the present study with results from the literature, the best evidence was found for segregation of QTL on BTA1 (FRT1; ICF) near $135 \mathrm{cM}$, BTA2 $\left(\mathrm{NRR}^{\mathrm{C}}\right)$ near $4 \mathrm{cM}$, BTA9 $\left(\mathrm{IFL}^{\mathrm{C}}\right)$ near $50 \mathrm{cM}$, BTA10 $\left(\mathrm{IFL}^{\mathrm{C}}\right.$ ) near $91 \mathrm{cM}, \mathrm{BTA} 24(\mathrm{ICF})$ near $6 \mathrm{cM}$, and BTA26 $\left(\right.$ IFL $^{\mathrm{C}}$; NRR ${ }^{\mathrm{H}}$; FRT1) near $50 \mathrm{cM}$. Despite high $q$-values, BTA10 was included in the best evidence as the QTL for IFL ${ }^{\mathrm{C}}$ and the suggestive QTL for AIS ${ }^{\mathrm{C}}$ were within $20 \mathrm{cM}$ and shared 5 same segregating sires. In this study, BTA26 was included among the best evidence because QTL for IFL ${ }^{\mathrm{C}}, \mathrm{NRR}^{\mathrm{H}}$, and FRT1 are located within $25 \mathrm{cM}$.

\section{Overlap Between Studies}

Generally, the QTL found in different studies were not entirely consistent with each other. The best overlap between our results and previously published results was found with the studies of Boichard et al. (2003) and Schulman et al. (2008). Boichard et al. (2003) studied the French Holstein population, which being of the same breed provides an additional support to our findings. Additionally, the overlap between our results and the results of Schulman et al. (2008) provides additional support, considering that they studied the Finnish Ayrshire population, a different breed than Holstein.

However, power of detection in any of the experiments to detect QTL for low heritability traits is probably not high. Thereby, the probability of detection of the same QTL in different studies gets smaller. Also, 
trait definitions and strategies for editing phenotypic data, especially with respect to the handling of extreme records and censored data, differ among studies. This in turn may lead to disagreements about the presence of QTL. Finally, as can be seen from the $q$-values calculated for the results in the present study, a significant fraction of the QTL detected must by necessity be false positives. If one is willing to assume that closely spaced QTL for different traits represent the same underlying variation (an assumption that was not tested in this study), one can use results from multiple, biologically related traits to provide internal corroboration of the conclusions reached.

\section{Consistency Between QTL for Heifer and Cow Traits}

In this study, different QTL were detected for traits measured in cows and heifers. For the traits AIS, HST, IFL, and NRR, cows and heifers were analyzed separately. In our study, no convincing evidence was found for overlap between QTL affecting cow and heifer traits. This is consistent with other QTL studies in which traits are separated into cow and heifer traits (Holmberg and Andersson-Eklund, 2006) even though these authors analyzed traits different from the ones analyzed in the present study. It agrees with published studies of correlations between cow and heifer fertility traits. Jamrozik et al. (2005) found a genetic correlation between cows and heifers of 0.60 for NRR and 0.76 for AIS in Canadian Holstein cattle. Kuhn et al. (2006) found a genetic correlation for conception rate of 0.39 in American Holstein cattle along with 15 other breeds. Oltenacu et al. (1991) reported a genetic correlation between heifer and cow first-service conception rate of 0.59 for Swedish Red and White. These numbers indicate that fertility characteristics of high-producing cows and virgin heifers only share $1 / 3$ or less of their genetic variation. Also, studies have incomplete power and may detect false-positive results, further reducing the fraction of QTL regions overlapping between traits recorded in cows and heifers.

\section{CONCLUSIONS}

A total of 26 QTL for fertility traits on 17 chromosomes were identified. On each of BTA1, BTA7, BTA10, and BTA26, several QTL were detected within narrow regions for the fertility traits investigated in this study and segregated in several grandsire families. Additional support was found for the segregation of QTL for fertility traits on BTA2, BTA9, and BTA24. Considerable overlap was found between the results in the present study on results from previous studies in Holstein populations.
Several chromosomes were found to harbor linked QTL. It must be investigated whether these represent pleiotropic effects of the same underlying genetic variation or whether they represent linked genetic polymorphisms. This could be done by analyzing the relevant QTL regions within a variance components framework (Thomasen et al., 2008). This would allow an explicit comparison of competing models incorporating either pleiotropic QTL or linked QTL. The same approach could be taken to examine the QTL detected in this study for correlated effects on other traits in the breeding goal. Unfavorable genetic correlations between yield and female fertility traits as well as low heritabilities of female fertility traits make it difficult to achieve genetic gain on fertility traits using conventional selection methods. However, QTL identified in this and other studies should be inspected for adverse effects on other traits included in breeding goals.

\section{ACKNOWLEDGMENTS}

We thank the Danish Cattle Federation (Århus, Denmark), Swedish Dairy Association (Stockholm, Sweden) and Nordic Cattle Genetic Evaluation for providing phenotypic data. This project was funded by FREM98 DJF: New technologies in farm animal breeding, and grant no. 34016503 136: DNA-based selection to improve disease resistance, fertility, calf survival and production in Danish dairy cattle from the Danish Directorate for Food, Fisheries and Agri Business (Copenhagen, Denmark) grant no. 3401-04-00853 and the Swedish Farmers' Foundation for Agricultural Research (Stockholm, Sweden) with co-funding from Viking Genetics. Viking Genetics is also acknowledged for providing semen samples. A. J. (Bart) Buitenhuis and Goutam Sahana (Århus University) are gratefully acknowledged for numerous and valuable discussions about QTL mapping and technical support. We thank Nicolas Friggens and Henrik Callesen (Århus University) for their input on reproductive physiology.

\section{REFERENCES}

Ancker, S., E. Norberg, and H. Callesen. 2006. Vidensyntese reproduction 113. Dansk Landbrugsrådgivning (Danish Agricultural Advisory Service), Aarhus, Denmark.

Ashwell, M. S., D. W. Heyen, T. S. Sonstegard, C. P. Van Tassell, Y. Da, P. M. VanRaden, M. Ron, J. I. Weller, and H. A. Lewin. 2004. Detection of quantitative trait loci affecting milk production, health, and reproductive traits in Holstein cattle. J. Dairy Sci. $87: 468-475$.

Boichard, D., C. Grohs, F. Bourgeois, F. Cerqueira, R. Faugeras, A. Neau, R. Rupp, Y. Amigues, M. Y. Boscher, and H. Levéziel. 2003. Detection of genes influencing economic traits in three French dairy cattle breeds. Genet. Sel. Evol. 35:77-101.

Churchill, G. A., and R. W. Doerge. 1994. Empirical threshold values for quantitative trait mapping. Genetics 138:963-971. 
Dematawewa, C. M. B., and P. J. Berger. 1998. Genetic and phenotypic parameters for 305-day yield, fertility, and survival in Holsteins. J. Dairy Sci. 81:2700-2709.

Dempster, A. P., N. M. Laird, and D. B. Rubin. 1977. Maximum likelihood from incomplete data via EM algorithm. J. R. Stat. Soc. B 39:1-38.

Haley, C. S., and S. A. Knott. 1992. A simple regression method for mapping quantitative trait loci in line crosses using flanking markers. Heredity 69:315-324.

Holmberg, M., and L. Andersson-Eklund. 2006. Quantitative trait loci affecting fertility and calving traits in Swedish dairy cattle. J. Dairy Sci. 89:3664-3671.

Holmberg, M., G. Sahana, and L. Andersson-Eklund. 2007. Fine mapping of a quantitative trait locus on chromosome 9 affecting non-return rate in Swedish dairy cattle. J. Anim. Breed. Genet. 124:257-263.

Jamrozik, J., J. Fatehi, G. J. Kistemaker, and L. R. Schaeffer. 2005. Estimates of genetic parameters for Canadian Holstein female production traits. J. Dairy Sci. 88:2199-2208.

Kühn, Ch., J. Bennewitz, N. Reinsch, N. Xu, H. Thomsen, C. Looft, G. A. Brockmann, M. Schwerin, C. Weimann, S. Hiendleder, G. Erhardt, I. Medjugorac, M. Förster, B. Brenig, F. Reinhardt, R. Reents, I. Russ, G. Averdunk, J. Blümel, and E. Kalm. 2003. Quantitative trait loci mapping of functional traits in the German Holstein cattle population. J. Dairy Sci. 86:360-368.

Kuhn, M. T., J. L. Hutchison, and G. R. Wiggans. 2006. Characterization of Holstein heifer fertility in the United States. J. Dairy Sci. 89:4907-4920.

Oltenacu, P. A., A. Frick, and B. Lindhé. 1991. Relationship of fertility to milk yield in Swedish cattle. J. Dairy Sci. 74:264-268.

Pryce, J. E., R. F. Veerkamp, R. Thompson, W. G. Hill, and G. Simm. 1997. Genetic aspects of common health disorders and measures of fertility in Holstein Friesian dairy cattle. Anim. Sci. 65:353-360.
Roxström, A., E. Strandberg, B. Berglund, U. Emanuelson, and J. Philipsson. 2001. Genetic and environmental correlations among female fertility traits and milk production in different parities of Swedish Red and White dairy cattle. Acta Agric. Scand. A 51:7-14.

Schnabel, R. D., T. S. Sonstegard, J. F. Taylor, and M. S. Ashwell. 2005. Whole-genome scan to detect QTL for milk production, conformation, fertility and functional traits in two US Holstein families. Anim. Genet. 36:408-416.

Schrooten, C., H. Bovenhuis, W. Coppieters, and J. A. M. Van Arendonk. 2000. Whole genome scan to detect quantitative trait loci for conformation and functional traits in dairy cattle. J. Dairy Sci. 83:795-806.

Schulman, N. F., G. Sahana, M. S. Lund, S. M. Viitala, and J. H. Vilkki. 2008. Quantitative trait loci for fertility traits in Finnish Ayrshire cattle. Genet. Sel. Evol. 40:195-214.

Sørensen, A. C., T. Lawlor, and F. Ruiz. 2007. A survey on fertility in the Holstein populations of the world. Page 17 in Proc Fertility in Dairy Cows - Bridging the Gaps. Liverpool Hope University, Liverpool, UK.

Storey, J. D., and R. Tibshirani. 2003. Statistical significance for genome-wide experiments. Proc. Natl. Acad. Sci. USA 100:9440 9445 .

Strudsholm, F., M. B. Almskou, A. Fogh, D. Boelling, U. S. Nielsen, and J. Pedersen. 2007. Arsstatistik, Avl 2006-2007. Report no. 118. Danish Agricultural Advisory Service, Aarhus, Denmark.

Thomasen, J. R.. B. Guldbrandtsen, P. Sørensen, B. Thomsen, and M. S. Lund. 2008. Quantitative trait loci affeting calving traits in Danish Holstein cattle. J. Dairy Sci. 91:2098-2105.

Weller, J. I., Y. Kashi, and M. Soller. 1990. Power of daughter and granddaughter designs for determining linkage between marker loci and quantitative trait loci in dairy cattle. J. Dairy Sci. 73:25252537 . 